\title{
COMPARATIVE STUDY OF META-HEURISTIC AND CLASSICAL TECHNIQUES FOR AUTOMATIC GENERATION CONTROL OF A MULTI-SOURCE SINGLE- AREA HYDRO-THERMAL-GAS POWER SYSTEM
}

Demilade D. Dinakin ${ }^{1}$ and Peter O. Oluseyi ${ }^{2}$

${ }^{1}$ Department of Electrical and Electronics Engineering, University of Lagos, Nigeria. Email: zemidinak@gmail.com

${ }^{2}$ Department of Electrical and Electronics Engineering, University of Lagos, Nigeria. Email: poluseyi@unilag.edu.ng

\begin{abstract}
The PID controller still remains a widely used and very effective means of achieving stability in control systems. Generally, the performance of the controller is determined by the proportional, integral and derivative gains of the controller. The classical techniques: ZieglerNichols (ZN) open loop method; ZN closed loop method; Chien-Hrones-Reswick (C-H-R) load rejection method; and meta-heuristic technique: the fuzzy logic algorithm, are used to determine the tuning parameters of the PID controller in this study. The performance comparison of these controllers is done for automatic generation control (AGC) of a multi-source single-area hydrothermal-gas power system. In such power systems, each source has a participation factor that determines its contribution to total power generation. The root mean square error (RMSE) is deployed to determine the proportionate balance of each generator's output with its corresponding participation factor. The performance comparison of the controllers using Simulink/MATLAB shows that the fuzzy-PID controller achieved the most proportionate generation balance.
\end{abstract}

\section{KEYWORDS}

Automatic generation control, frequency stability, meta-heuristic, multi-source, classical techniques, fuzzy-PID. 


\section{INTRODUCTION}

It has widely been reported that load disturbances in power systems result in corresponding system frequency changes (Fitri et al., 2017; Rahman et al., 2017). One of the main objectives of automatic generation control (AGC) is to sustain the system frequency as close to nominal as possible or within the specified range. The AGC is the system for adjusting the power output of generators. These generators usually receive kinetic energy from turbines which in turn receive potential energy from various fuel sources which include: hydro, steam (thermal), gas (combustion), wind, etc. Each of these sources acts alone in single-source power generation. Meanwhile, when two or more are combined, they create multi-source power generation. In multi-source (hybrid) power generation, each generator has a participation factor that determines its contribution to total power generation. The generators' outputs change in proportion to its participation factor. It has been established that the summation of participation factors of all participating generators, in each control area, is equal to unity (Barisal and Mishra, 2017).

The AGC has received attention in literature for several years now. According to Barisal and Mishra (2017), AGC was initiated by Cohn (1957). In the past decades, various works on AGC (Debnath et al., 2017; Elsisi et al., 2015; Jadhav and Vadirajacharya, 2012; Panigrahi et al., 2017; Pradhan et al., 2017; Rajesh and Rajagopal, 2017) have been proposed and implemented. It is readily observed in these works that the proportional-integral-derivative (PID) controller was used and various techniques were used to determine the gains of the PID controller. A PID controller continuously estimates an error value as the difference between a desired set point and a measured process variable and applies a correction based on the contribution of the proportional, integral, and derivative terms (Chen, 1996).

Techniques for determining the gains of the PID controller can basically be categorized into classical techniques and meta-heuristic techniques. The most widely used classical technique for PID tuning is the Ziegler-Nichols (ZN) tuning methods. Kumar and Patra (2016) applied ZN methods for tuning PID controller for a fourth order plant; Chandrakala et al. (2014) used $\mathrm{ZN}$ method to tune PI controllers of a designed multi-source multi-area system by keeping the process under closed-loop P control; Singh and Singh (2014) compared ZN tuned PID controllers for load frequency control of electrical plants using Matlab/Simulink. Basically, Ziegler-Nichols has two PID tuning methods: closed loop method and open loop method. The $\mathrm{ZN}$ closed loop method is often used more than the $\mathrm{ZN}$ open loop method. However, in this paper, both methods would be used for tuning the PID controller in order to ascertain the 
effectiveness of both methods. Another classical tuning technique is the Chien-Hrones-Reswick (C-H-R) method which is a modification of the $\mathrm{ZN}$ open loop method. Chien, Hrones and Reswick made an observation that there is a difference when tuning for set point response and load disturbance response (Oonsivilai and Marungsri, 2007). Since AGC is aimed at tackling load disturbances, the C-H-R load rejection ( $0 \%$ overshoot) method is also used to determine the gains of the PID controller.

Various meta-heuristics methods have also been proposed and implemented for AGC and very good results were achieved. Guha et al. (2016) utilized quasi-oppositional grey wolf optimization algorithm for load frequency control of a large scale power system; Sahu et al. (2016) employed teaching learning based optimization algorithm for AGC of multi-area power systems with diverse energy sources; Oonsivilai and Marungsri (2007) optimally tuned PID controllers for an AGC system using adaptive tabu search while Panwar and Chahar (2016) compared a fuzzy tuned PID controller with ZN tuned PI and PID controllers for automatic load frequency control of a three-area power system. A meta-heuristic is a general-purpose algorithmic framework that can be applied to different optimization problems with relatively few modifications (Shakrokhi and Zomorrodi, 2012). It is formally defined as an iterative generation process which guides a subordinate heuristic by combining intelligently different concepts for exploring and exploiting the search space using learning strategies to structure information in order to find efficiently near-optimal solutions (Dorigo and Gambardella, 1997). A widely used meta-heuristic technique is the fuzzy logic control. Fuzzy logic has proved to be a powerful tool in various fields due to the fact that it can readily accommodate a wide range of operating conditions and it is more readily customizable in natural language terms (Osman and Laporte, 1996). Combining the FLC with the PID controller creates a hybrid self-tuning controller. This is usually termed as the Fuzzy-PID controller.

In this paper, a multi-source (hydro, thermal and gas) single-area power system is modeled. Classical control techniques (ZN and C-H-R methods) and meta-heuristic technique (Fuzzy Logic) are used to determine the gains of the PID controller for AGC of the power system. The participation factors of the generators are varied to compare the proportionate balance of the generators' outputs of each source with its participation factor using the root mean square error (RMSE). The dynamic performances of the $\mathrm{ZN}, \mathrm{C}-\mathrm{H}-\mathrm{R}$ and fuzzy logic tuned controllers are then compared using the following performance indices: integral square error (ISE), integral absolute error (IAE), integral time squared error (ITSE) and integral time absolute error (ITAE). 


\section{METHODOLOGY}

\subsection{Power system model}

Fig. 1 shows the model of a multi-source single area power system. It comprises of hydro, thermal and gas generating units. The hydro unit has a hydraulic speed governor which is the main controller of the hydraulic turbine. The governor varies the water flow through the turbine to control its speed or power output (Al-Odienat and Al-Lawama, 2008). Similarly, the steam unit has its speed governor. Apparently, the governor controls the flow of steam into the turbine according to the power generation output. The steam unit also has a reheat turbine which is considered as prime mover for higher thermal efficiency (Thapar, 2015). In the case of the gas unit, the fuel system is associated with the valve positioner and the fuel system actuator. The valve positioner provides a control pressure to the actuator for controlling the valve. The fuel system generates the fuel supply signal based on fuel demand signal (Sarumathi et al., 2016).

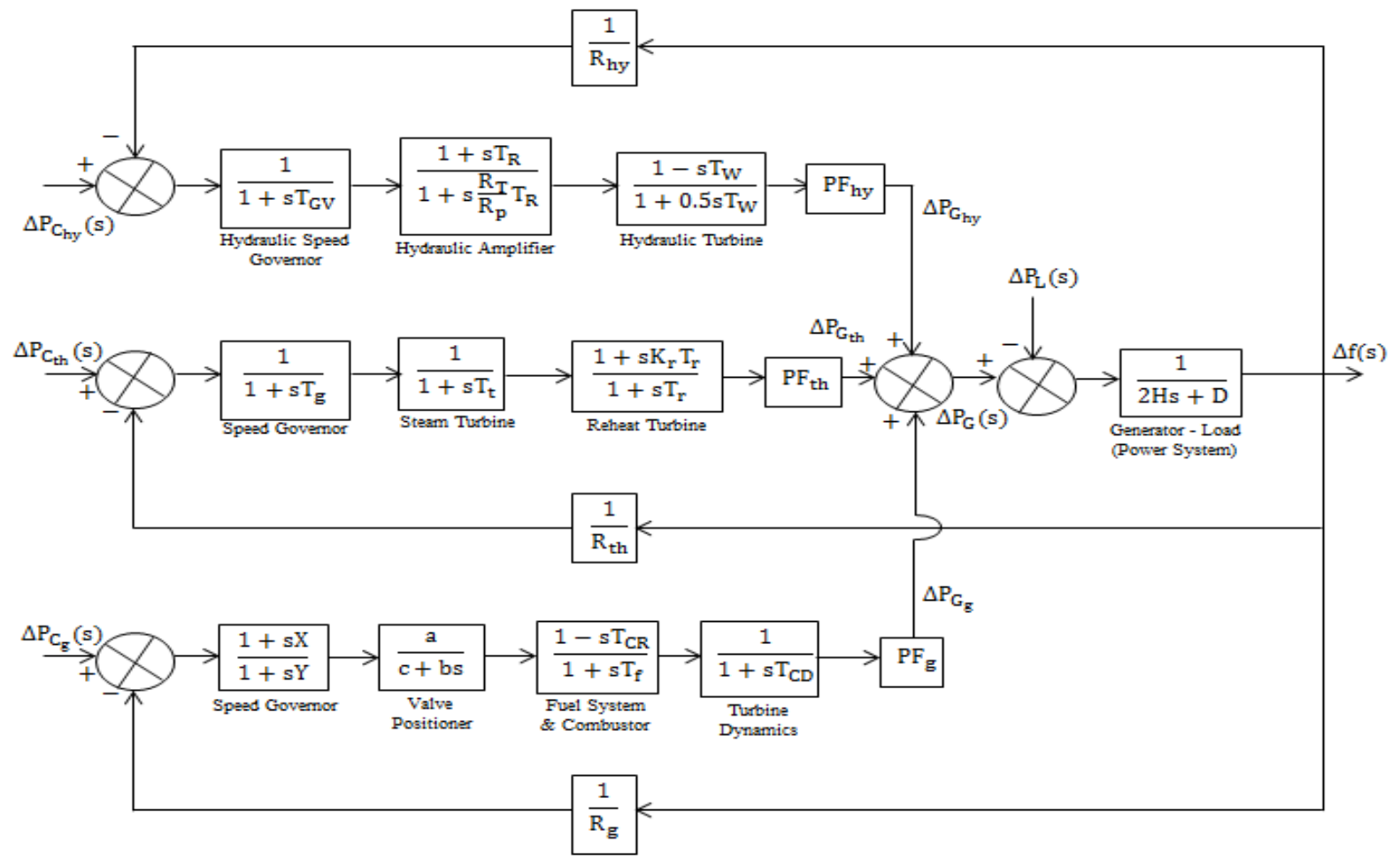

Fig. 1. A multi-source single-area hydro-thermal-gas power system.

The transfer function of a closed loop system with a positive feedback is given by (1).

$$
\frac{C(s)}{R(s)}=\frac{G(s)}{1-G(s) H(s)}
$$

Where $\mathrm{G}(\mathrm{s})$ is the transfer function of the plant/process and $\mathrm{H}(\mathrm{s})$ is the feedback. If we assume that:

$\mathrm{N}=\left(\mathrm{sT}_{\mathrm{GV}}+1\right)\left(0.5 \mathrm{~s} \mathrm{~T}_{\mathrm{W}}+1\right)\left(\mathrm{sR}_{\mathrm{T}} \mathrm{T}_{\mathrm{R}}+\mathrm{R}_{\mathrm{hy}}\right)\left(\mathrm{sT} \mathrm{T}_{\mathrm{g}}+1\right)\left(\mathrm{s} \mathrm{T}_{\mathrm{r}}+1\right)\left(\mathrm{sT}_{\mathrm{t}}+1\right)(\mathrm{sY}+1)(\mathrm{sb}+\mathrm{c})\left(\mathrm{s} \mathrm{T}_{\mathrm{f}}+1\right)\left(\mathrm{sT}_{\mathrm{CD}}+1\right) \mathrm{R}_{\mathrm{th}} \mathrm{R}_{\mathrm{g}}$ 


$$
\begin{aligned}
& 0=(2 H s+D)\left(s T_{G V}+1\right)\left(0.5 s T_{W}+1\right)\left(s R_{T} T_{R}+R_{h y}\right)\left(s T_{g}+1\right)\left(s T_{r}+1\right)\left(s T_{t}+1\right)(s Y+1)(s b+c)\left(s T_{f}+1\right)\left(s T_{C D}+1\right) R_{t h} R_{g} \\
& \mathrm{P}=\left(s \mathrm{~T}_{\mathrm{R}}+1\right)\left(s \mathrm{~s}_{\mathrm{w}}-1\right)\left(\mathrm{sT} \mathrm{T}_{\mathrm{g}}+1\right)\left(s \mathrm{~s}_{\mathrm{r}}+1\right)\left(s \mathrm{~s}_{\mathrm{t}}+1\right)(\mathrm{sY}+1)(\mathrm{sb}+\mathrm{c})\left(\mathrm{s} \mathrm{T}_{\mathrm{f}}+1\right)\left(\mathrm{s} \mathrm{T}_{\mathrm{CD}}+1\right) \mathrm{PF}_{\mathrm{hy}} \mathrm{R}_{\mathrm{th}} \mathrm{R}_{\mathrm{g}} \\
& \mathrm{Q}=\left(s \mathrm{r}_{\mathrm{r}} \mathrm{T}_{\mathrm{r}}+1\right)\left(\mathrm{sT}_{\mathrm{GV}}+1\right)\left(0.5 s \mathrm{~T}_{\mathrm{W}}+1\right)\left(\mathrm{sR}_{\mathrm{T}} \mathrm{T}_{\mathrm{R}}+\mathrm{R}_{\mathrm{hy}}\right)(\mathrm{sY}+1)(\mathrm{sb}+\mathrm{c})\left(\mathrm{sT}_{\mathrm{f}}+1\right)\left(\mathrm{sT}_{\mathrm{CD}}+1\right) \mathrm{PF}_{\mathrm{th}} \mathrm{R}_{\mathrm{g}} \\
& R=(s X+1)\left(1-s T_{C R}\right)\left(s T_{G V}+1\right)\left(0.5 s T_{W}+1\right)\left(s R_{T} T_{R}+R_{h y}\right)\left(s T_{g}+1\right)\left(s T_{r}+1\right)\left(s T_{t}+1\right) a P F_{g} R_{t h}
\end{aligned}
$$

Then the overall transfer function of the system shown in Fig. 1 is given by (2).

$$
\frac{\Delta \mathrm{f}(\mathrm{s})}{-\Delta \mathrm{P}_{\mathrm{L}}(\mathrm{s})}=\frac{\mathrm{N}}{\mathrm{O}-\mathrm{P}-\mathrm{Q}-\mathrm{R}}
$$

For normal system operating condition, the total generation, $\mathrm{P}_{\mathrm{G}}$, is the sum of generation by each fuel source. This is given by:

$$
\mathrm{P}_{\mathrm{G}}=\mathrm{P}_{\mathrm{G}_{\mathrm{hy}}}+\mathrm{P}_{\mathrm{G}_{\mathrm{th}}}+\mathrm{P}_{\mathrm{G}_{\mathrm{g}}}
$$

$\mathrm{PF}_{\mathrm{hy}}, \mathrm{PF}_{\text {th }}$ and $\mathrm{PF}_{\mathrm{g}}$ represent the participation factors of the hydro, thermal and gas source respectively which determines their contributions to the total power generation. The sum of the participation factors is equal to unity.

$$
\mathrm{PF}_{\mathrm{hy}}+\mathrm{PF}_{\mathrm{th}}+\mathrm{PF}_{\mathrm{g}}=1
$$

From Fig. 1, the governor actions ensure that a large and sudden frequency fall or rise is prevented. This is known as primary control. However, to restore system frequency to its nominal value, secondary control (AGC) is required. To achieve secondary control, a negative feedback is introduced, weighted by a frequency bias constant, $\beta$, to the system. The frequency bias constant for a damping factor, $\mathrm{D}$, is given by (5).

$$
\beta=\frac{1}{R}+D
$$

For the hydro unit, the temporary droop, $\mathrm{R}_{\mathrm{T}}$, is calculated using (6).

$$
\mathrm{R}_{\mathrm{T}}=\left[2.3-\left(\mathrm{T}_{\mathrm{W}}-1\right) 0.15\right] \frac{\mathrm{T}_{\mathrm{W}}}{2 \mathrm{H}}
$$

The reset time, $T_{R}$, is also calculated using (7).

$$
\mathrm{T}_{\mathrm{R}}=\left[5-\left(\mathrm{T}_{\mathrm{W}}-1\right) 0.5\right] \mathrm{T}_{\mathrm{W}}
$$

The parameters for the hydro, thermal (Jagatheesan et al., 2017) and gas (Moghadam and Jalilzadeh, 2014) plants used in modeling the power system are shown in Table 1. 
Table 1. Parameters used in modelling the power system.

\begin{tabular}{lll}
\hline Source & Parameter & Value \\
\hline \multirow{5}{*}{ Hydro } & Inertia constant $(\mathrm{H})$ & $5 \mathrm{~s}$ \\
& Damping factor $(\mathrm{D})$ & $0.5 \mathrm{pu}$ \\
& Nominal frequency $(\mathrm{f})$ & $50 \mathrm{~Hz}$ \\
& Time constant $\left(\mathrm{T}_{\mathrm{GV}}\right)$ & $0.2 \mathrm{~s}$ \\
& Reset time $\left(\mathrm{T}_{\mathrm{R}}\right)$ & $5 \mathrm{~s}$ \\
& Temporary droop $\left(\mathrm{R}_{\mathrm{T}}\right)$ & $0.23 \mathrm{~s}$ \\
& Permanent droop $\left(\mathrm{R}_{\mathrm{P}}\right)$ & $0.046 \mathrm{~s}$ \\
& Water starting time $\left(\mathrm{T}_{\mathrm{W}}\right)$ & $1 \mathrm{~s}$ \\
& Regulation parameter $\left(\mathrm{R}_{\mathrm{hy}}\right)$ & $2.4 \mathrm{~Hz} / \mathrm{puMW}$ \\
& Frequency bias constant $\left(\beta_{\mathrm{hy}}\right)$ & $0.9167 \mathrm{puMW} / \mathrm{Hz}$ \\
& Speed governor time constant $\left(\mathrm{T}_{\mathrm{g}}\right)$ & $0.2 \mathrm{~s}$ \\
& Speed reheat turbine time constant $\left(\mathrm{T}_{\mathrm{t}}\right)$ & $0.3 \mathrm{~s}$ \\
& Steam turbine reheat coefficient $\left(\mathrm{K}_{\mathrm{r}}\right)$ & $0.5 \mathrm{~s}$ \\
& Steam turbine reheat time constant $\left(\mathrm{T}_{\mathrm{r}}\right)$ & $10 \mathrm{~s}$ \\
& Regulation parameter $\left(\mathrm{R}_{\mathrm{th}}\right)$ & $2.4 \mathrm{~Hz} / \mathrm{puMW}$ \\
& Frequency bias constant $\left(\beta_{\mathrm{th}}\right)$ & $0.9167 \mathrm{puMW} / \mathrm{Hz}$ \\
& Speed governor lead time constant $(\mathrm{X})$ & $0.6 \mathrm{~s}$ \\
& Speed governor lag time constant $(\mathrm{Y})$ & $1 \mathrm{~s}$ \\
& Valve position constants $(\mathrm{a}, \mathrm{b}, \mathrm{c})$ & $1,0.05,1$ \\
& Combustion reaction time delay $\left(\mathrm{T}_{\mathrm{CR}}\right)$ & $0.3 \mathrm{~s}$ \\
& Fuel time constant $\left(\mathrm{T}_{\mathrm{f}}\right)$ & $0.23 \mathrm{~s}$ \\
& Compressor discharge volume $\left(\mathrm{T}_{\mathrm{CD}}\right)$ & $0.2 \mathrm{~s}$ \\
& Regulation parameter $\left(\mathrm{R}_{\mathrm{g}}\right)$ & $2.4 \mathrm{~Hz} / \mathrm{puMW}$ \\
& Frequency bias constant $\left(\beta_{\mathrm{g}}\right)$ & $0.9167 \mathrm{puMW} / \mathrm{Hz}$ \\
\hline
\end{tabular}

The overall system model is shown in Fig. 2.

\subsection{Design of the controllers}

The controller used is the PID controller which is tuned using Ziegler-Nichols $(\mathrm{ZN})$ open loop and closed loop methods, the Chien, Hrones and Reswick (C-H-R) load rejection method and the Fuzzy Logic Controller (FLC). This is for the purpose of determining the effectiveness and efficiency of each tuning mechanism. An ideal PID controller has the transfer function:

$$
\mathrm{G}_{\mathrm{c}}(\mathrm{s})=\mathrm{K}_{\mathrm{P}}\left[1+\frac{1}{\mathrm{~T}_{\mathrm{I}} \mathrm{S}}+\mathrm{T}_{\mathrm{D}} \mathrm{s}\right]
$$

$K_{p}$ is the proportional gain of the controller, $\tau_{i}$ is the integral time constant while $\tau_{d}$ is the derivative time constant. 


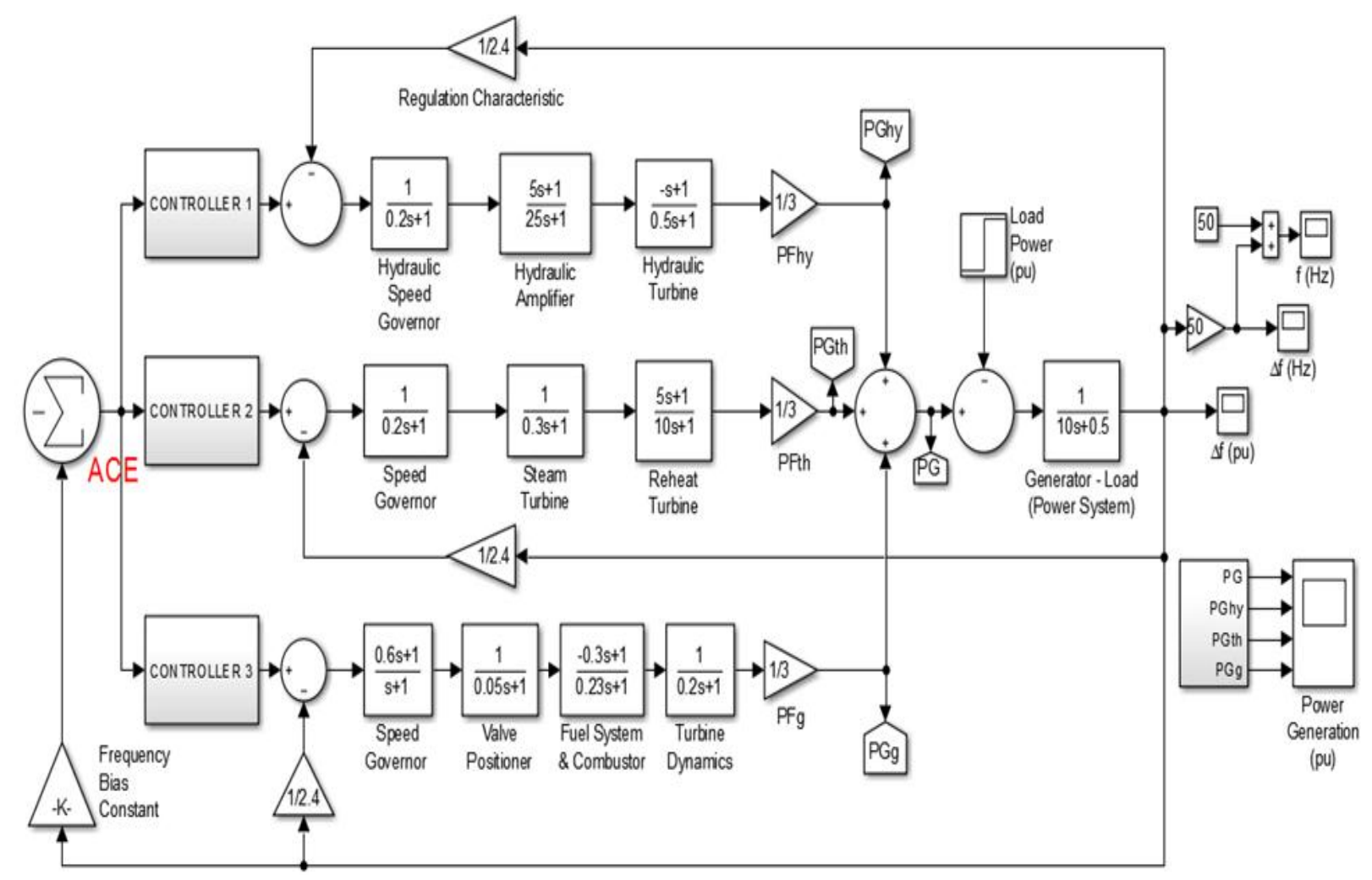

Fig. 2. Overall transfer function representation of the power system.

\subsubsection{Ziegler-Nichols open loop and Chien-Hrones-Reswick methods}

Ziegler and Nichols tuning methods are PID controller tuning methods through which the parameters of the controller are applied to the process or plant for optimal performance. The $\mathrm{ZN}$ open loop method is a robust and popular method for PID controller tuning. When using this method, the unit-step response of the system's open loop transfer function must exhibit an s-shape curve (point of inflection). This curve is characterized by the parameters: delay time, L, time constant, T, and gain, K, (Abdulameer et al., 2016). This is shown in Fig. 3 (Astrom and Hagglund, 1995).

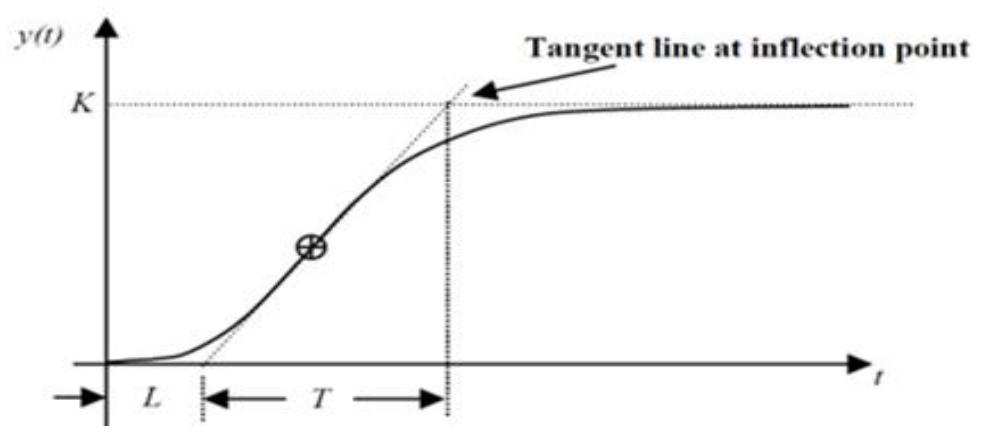

Fig. 3. Parameters for Ziegler-Nichols open loop tuning (Astrom and Hagglund, 1995) 
The C-H-R method is also an open loop method. It is, in fact, a modification of the ZN open loop method because the tuning parameters are also based on the delay time and time constant of the system's open loop step response. The C-H-R method has different tuning parameters for set point responses and load disturbance responses (Shakrokhi and Zomorrodi, 2012). The $\mathrm{ZN}$ open loop method and C-H-R load rejection ( $0 \%$ overshoot) tuning parameters for the PID controller are shown in Table 2.

Table 2. Parameters for the PID controller

\begin{tabular}{cccc}
\hline Tuning method & $\mathbf{K}_{\mathbf{P}}$ & $\mathbf{T}_{\mathbf{i}}$ & $\mathbf{T}_{\mathbf{d}}$ \\
\hline ZN open loop & $\frac{1.2}{\mathrm{~K}} \frac{\mathrm{T}}{\mathrm{L}}$ & $2 \mathrm{~L}$ & $0.5 \mathrm{~L}$ \\
C-H-R load Rejection (0\% overshoot) & $\frac{0.95}{\mathrm{~K}} \frac{\mathrm{T}}{\mathrm{L}}$ & $2.4 \mathrm{~L}$ & $0.42 \mathrm{~L}$ \\
\hline
\end{tabular}

The primary loop transfer functions of the hydro, thermal and gas sources respectively when acting alone are:

$$
\begin{aligned}
\frac{\Delta \mathrm{f}}{\Delta \mathrm{P}_{\mathrm{C}_{\mathrm{hy}}}} & =\frac{-5 \mathrm{~s}^{2}+4 \mathrm{~s}+1}{25 \mathrm{~s}^{4}+177.3 \mathrm{~s}^{3}+263.7 \mathrm{~s}^{2}+24.52 \mathrm{~s}+0.9167} \\
\frac{\Delta \mathrm{f}}{\Delta \mathrm{P}_{\mathrm{Ch}}} & =\frac{5 \mathrm{~s}+1}{6 \mathrm{~s}^{4}+50.9 \mathrm{~s}^{3}+107.5 \mathrm{~s}^{2}+17.33 \mathrm{~s}+0.9167} \\
\frac{\Delta \mathrm{f}}{\Delta \mathrm{P}_{\mathrm{Cg}}} & =\frac{-0.18 \mathrm{~s}^{2}+0.3 \mathrm{~s}+1}{0.023 \mathrm{~s}^{5}+0.6992 \mathrm{~s}^{4}+5.51 \mathrm{~s}^{3}+15 \mathrm{~s}^{2}+10.87 \mathrm{~s}+0.9167}
\end{aligned}
$$

The step responses of the transfer functions are shown in Fig. 4.

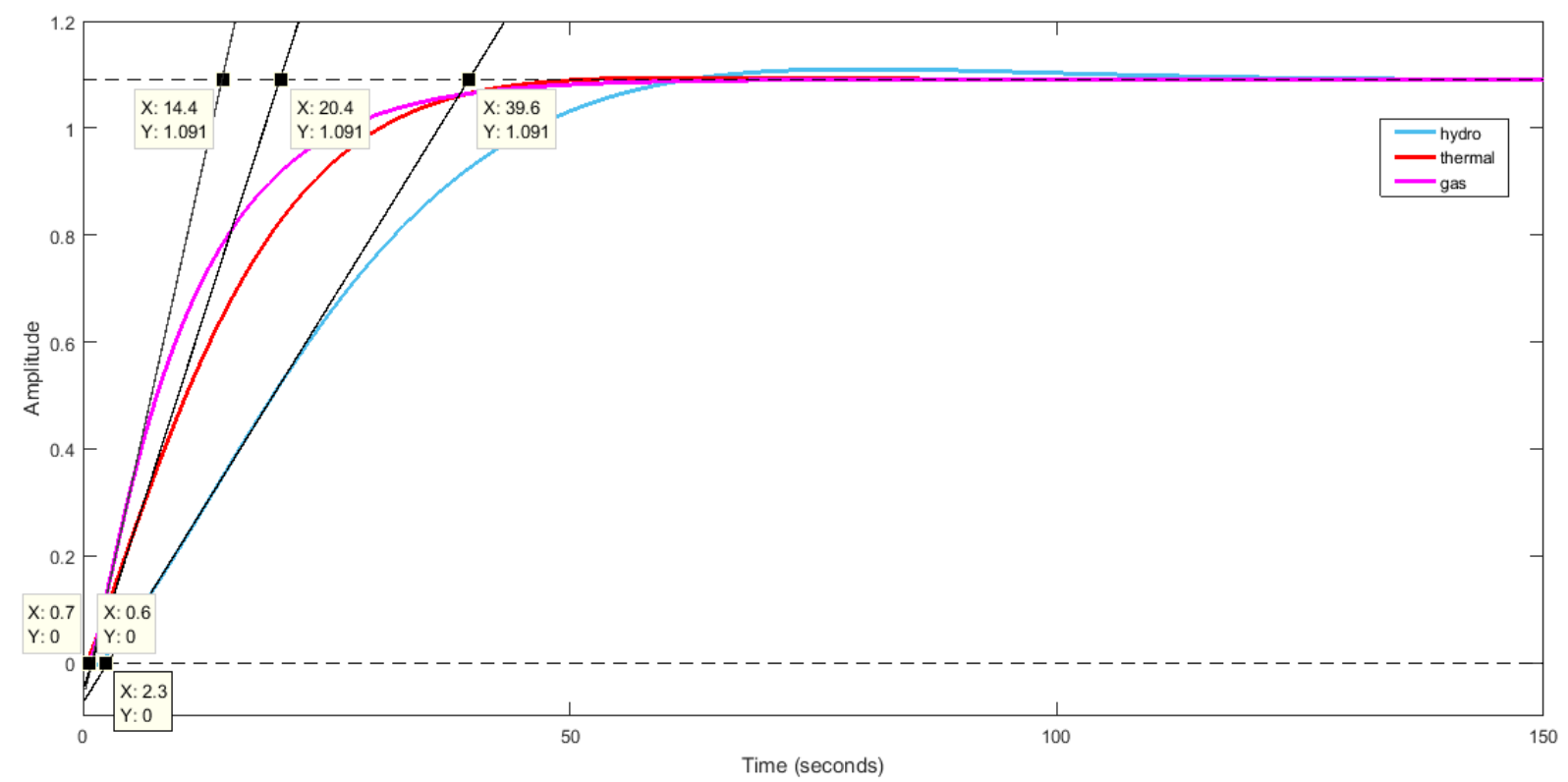

Fig. 4. Primary loop step response. 
From Fig. 4, the delay time, L, and time constants, T, for each source, as well as the tuning parameters of the ZN open loop and C-H-R load rejection methods for the PID controller, using Table 2, are shown in Table 3.

Table 3. PID controller parameters using ZN open loop and C-H-R methods.

\begin{tabular}{ccccccc}
\hline Tuning method & Source & $\mathbf{T}$ & $\mathbf{L}$ & $\mathbf{K}$ & $\mathbf{T}_{\mathbf{i}}$ & $\mathbf{T}_{\mathbf{d}}$ \\
\hline ZN OL & Hydro & 37.3 & 2.30 & 1.091 & 4.60 & 1.15 \\
& Thermal & 19.8 & 0.60 & 1.091 & 1.20 & 0.30 \\
C-H-R & Gas & 13.7 & 0.70 & 1.091 & 1.40 & 0.35 \\
& Hydro & 37.3 & 2.30 & 1.091 & 5.52 & 0.97 \\
& Thermal & 19.8 & 0.60 & 1.091 & 1.44 & 0.25 \\
& Gas & 13.7 & 0.70 & 1.091 & 1.68 & 0.29 \\
\hline
\end{tabular}

\subsubsection{Ziegler-Nichols closed loop method}

This method has tremendously been implemented by earlier researchers. It is a trial and error method proposed by Ziegler and Nichols (1942). The tuning parameters of the PID controller for the ZN closed loop method are shown in Table 4 (Ziegler and Nichols, 1942).

Table 4. Tuning parameters of the PID controller for the ZN closed loop method.

\begin{tabular}{cccc}
\hline Control Type & $\mathbf{K}_{\mathbf{P}}$ & $\mathbf{T}_{\mathbf{i}}$ & $\mathbf{T}_{\mathbf{d}}$ \\
\hline Classic PID & $\mathbf{0 . 6 K _ { c u }}$ & $\mathbf{P}_{\mathbf{u}} / \mathbf{2}$ & $\mathbf{P}_{\mathbf{u}} / \mathbf{8}$ \\
Some overshoot & $\mathbf{0 . 3 3 K _ { \mathbf { c u } }}$ & $\mathbf{P}_{\mathbf{u}} / \mathbf{2}$ & $\mathbf{P}_{\mathbf{u}} / \mathbf{3}$ \\
No overshoot & $\mathbf{0 . 2 \mathbf { K } _ { \mathrm { cu } }}$ & $\mathbf{P}_{\mathbf{u}} / \mathbf{2}$ & $\mathbf{P}_{\mathbf{u}} / \mathbf{3}$ \\
\hline
\end{tabular}

The ultimate control gain, $\mathbf{K}_{\mathbf{c u}}$, is the proportional value for which the system exhibits sustained oscillation. The gain margin, $\mathbf{G}_{\mathbf{m}}$, of the system is equal to the ultimate control gain. This is obtained at a gain crossover frequency, $\boldsymbol{\omega}_{\mathbf{c g}}$.

$$
\mathbf{K}_{\mathbf{c u}}=\mathbf{G}_{\mathbf{m}}
$$

The ultimate or oscillation period, $\mathbf{P}_{\mathbf{u}}$ is calculated using (13).

$$
P_{u}=\frac{2 \pi}{\omega_{c g}}
$$




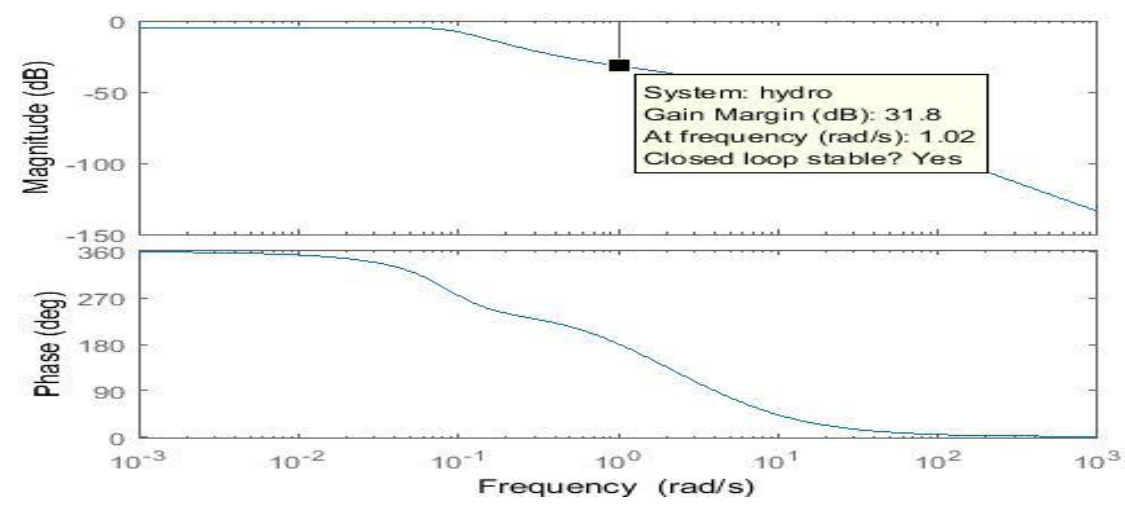

(a) hydro

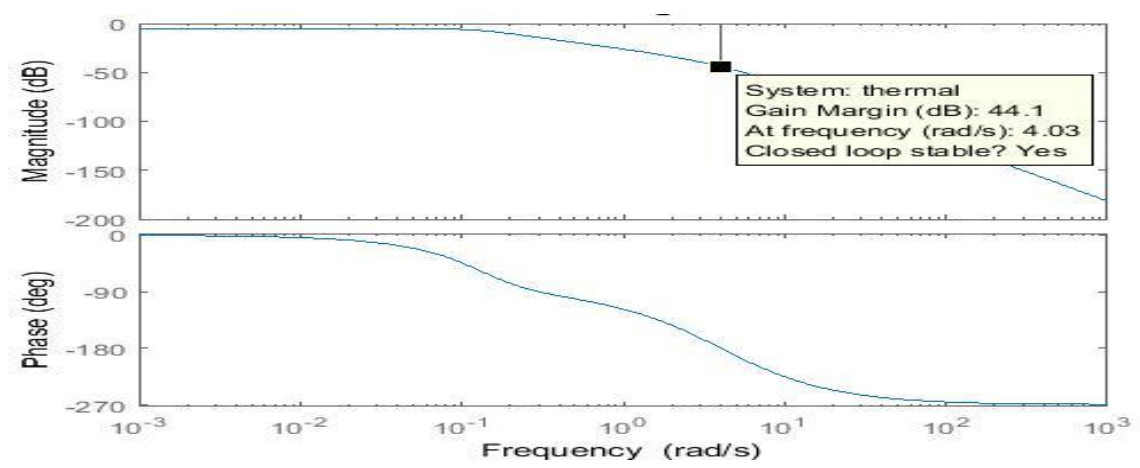

(b) thermal

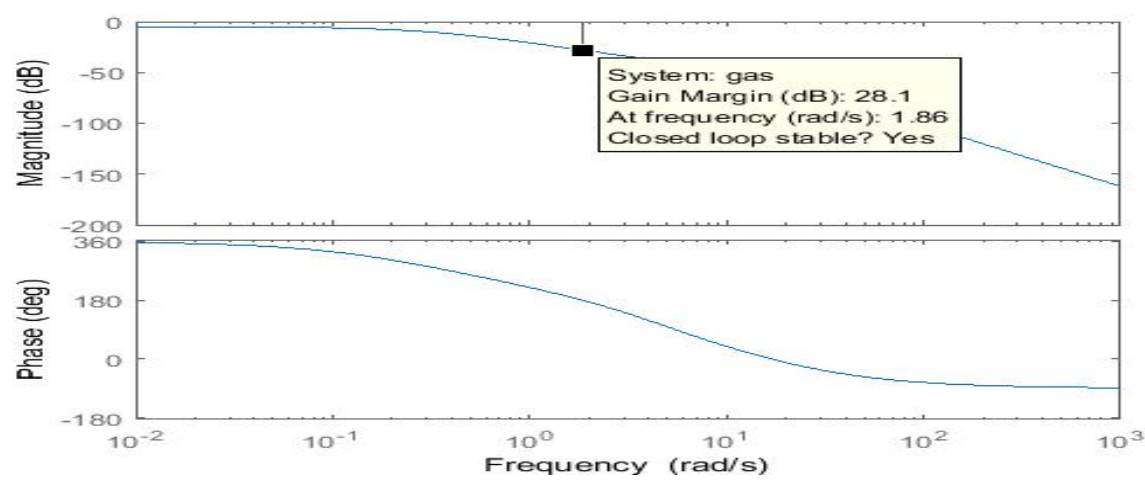

(c) gas

Fig. 5. Bode plots of the closed loop transfer functions.

From the Bode plots of the closed loop transfer function, in Fig. 5, of each source, the gain margins, $\mathbf{G}_{\mathbf{m}}$, and gain crossover frequencies, $\boldsymbol{\omega}_{\mathbf{c g}}$, are shown in Table 5. The ultimate periods, $\mathbf{P}_{\mathbf{u}}$, are also shown, as well as the integral time constants, $\mathbf{T}_{\mathbf{i}}$, and derivative time constants, $\mathbf{T}_{\mathbf{i}}$.

Table 5. PID controller parameters using ZN closed loop method.

\begin{tabular}{cccccc}
\hline Source & $\mathbf{G}_{\mathbf{m}}$ & $\mathbf{\omega}_{\mathbf{c g}}$ & $\mathbf{P}_{\mathbf{u}}$ & $\mathbf{T}_{\mathbf{i}}$ & $\mathbf{T}_{\mathbf{d}}$ \\
\hline Hydro & 31.8 & 1.02 & 6.16 & 3.08 & 2.05 \\
Thermal & 44.1 & 4.03 & 1.56 & 0.78 & 0.52 \\
Gas & 28.1 & 1.86 & 3.37 & 1.69 & 1.12 \\
\hline
\end{tabular}


The no-overshoot closed loop tuning parameters from Table 5 are used for the PID tuning. The proportional, integral and derivative gains of the controllers tuned using $\mathrm{ZN}$ open loop, $\mathrm{C}-\mathrm{H}-\mathrm{R}$ load rejection and $\mathrm{ZN}$ closed loop methods are shown in Table 6.

Table 6. PID gains of the controllers tuned using $\mathrm{ZN}$ and C-H-R methods.

\begin{tabular}{|c|c|c|c|c|c|c|c|c|c|}
\hline \multirow[t]{2}{*}{ Source } & \multicolumn{3}{|c|}{ ZN open loop } & \multicolumn{3}{|c|}{ C-H-R } & \multicolumn{3}{|c|}{ ZN closed loop } \\
\hline & $\mathbf{K}_{\mathbf{P}}$ & $\mathbf{K}_{\mathbf{i}}$ & $K_{d}$ & $\mathbf{K}_{\mathbf{P}}$ & $\mathbf{K}_{\mathbf{i}}$ & $\mathbf{K}_{\mathbf{d}}$ & $\mathbf{K}_{\mathbf{P}}$ & $\mathbf{K}_{\mathbf{i}}$ & $\mathbf{K}_{\mathbf{d}}$ \\
\hline Hydro & 17.84 & 3.88 & 20.52 & 14.12 & 2.56 & 13.70 & 6.36 & 2.06 & 13.04 \\
\hline Thermal & 36.30 & 30.25 & 10.89 & 28.73 & 19.95 & 4.99 & 8.82 & 11.31 & 4.59 \\
\hline Gas & 21.53 & 15.38 & 5.38 & 17.04 & 10.14 & 2.94 & 7.21 & 4.27 & 8.08 \\
\hline
\end{tabular}

\subsubsection{Fuzzy-PID controller}

The Fuzzy-PID Controller combines the Fuzzy Logic Controller (FLC) with the PID controller to create a hybrid controller. The Fuzzy interface is used to calculate the values of the PID control parameters $\left(\mathrm{K}_{\mathrm{p}}, \mathrm{K}_{\mathrm{i}}, \mathrm{K}_{\mathrm{d}}\right)$. Therefore, it works as an automatic tuner for the PID controller (Jain and Beniwal, 2015). A typical Fuzzy-PID controller is shown in Fig. 6.

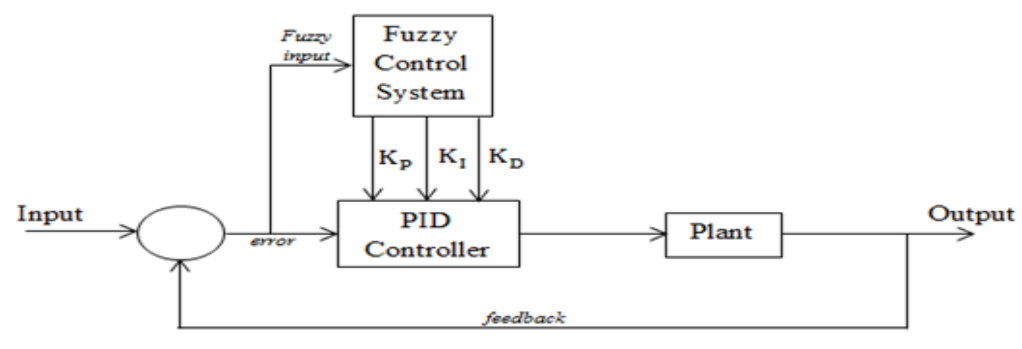

Fig. 6. A typical Fuzzy-PID controller.

Fuzzy Logic Control is described by a knowledge-based Algorithm. A Fuzzy Control System (FCS) basically involves three stages namely Fuzzification, Fuzzy Inference Process and Defuzzification. It requires a database which constitutes parameters obtained from the controlled object whereby this knowledge is used for fuzzification of the input and output. The numerical parameters of the input are converted into a linguistic value. This linguistic value is the fuzzy input. On the other hand, the fuzzy output is the linguistic value inferred by a rulebase as a result of the fuzzy input. In general, there are no systematic tools for forming the rulebase of the FLC (Reusch, 2006). The rule-base is made up of a group of logical rules that relate the input with the output of the FLC. The theoretical and practical understanding of the dynamics of the controlled object forms the basis for the knowledge behind the rule-base. In the design of the Fuzzy-PID controller, the area control error (ACE) and the rate of change of 
the ACE (ACE') are taken as the Fuzzy inputs while the proportional, derivative and integral gains of the PID controller are taken as the fuzzy outputs. This is shown in Fig. 7.

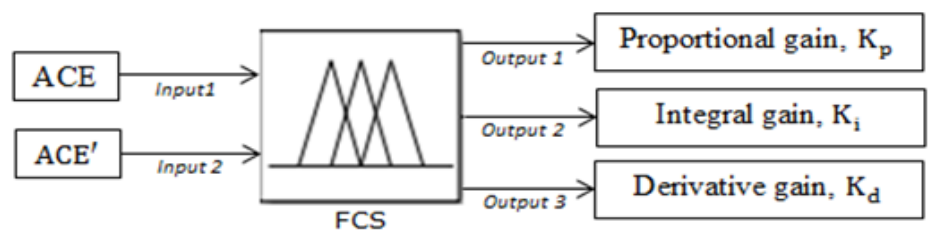

Fig. 7. Input and output variables for the fuzzy control system.

A Mamdani-type fuzzy inference system is used. All 5 inputs and outputs were mapped, using equally spaced Gaussian membership functions, into: \{very low (VL), low (L), medium (M), high $(\mathrm{H})$, very high $(\mathrm{VH})\}$. The rules relating the inputs with each output are shown in Table 7.

Table 7. Rules relating the inputs with each output.

\begin{tabular}{lccccc}
\hline ACE & VL & L & M & H & VH \\
\cline { 1 - 2 } & & & & & \\
L & VL & VL & L & L & M \\
M & VL & L & L & L & M \\
H & L & M & M & M & H \\
VH & M & H & H & H & VH \\
\hline
\end{tabular}

\subsection{Performance Indices}

Performance Indices are measures used to determine the performance of a control system design for a process. The performance indices are a function of the error signal. Examples include: the integral square error (ISE), the integral absolute error (IAE), the integral time squared error (ITSE) and the integral time absolute error (ITAE) etc. These performance indices are used as the fitness functions for the performance comparison of the tuned controllers, with the change in frequency $(\triangle \mathrm{f})$ taken as the error, $e(t)$.

In order to measure the proportionality balance between each generator's participating factor and its generation output, the root mean square error (RMSE) is used. The RMSE is the square root of the average of squared errors. It is used to measure the differences between values predicted by a model and observed values. It is given by (14).

$$
\operatorname{RMSE}=\sqrt{\frac{\sum_{\mathrm{i}=1}^{\mathrm{N}}\left(\widehat{\mathrm{y}}_{\mathrm{i}}-\mathrm{y}_{\mathrm{i}}\right)^{2}}{\mathrm{~N}}}
$$

In this case, $\hat{\mathbf{y}}_{\mathbf{i}}$ is the predicted/expected power generation and $\mathbf{y}_{\mathbf{i}}$ is the actual power generation. 


\section{RESULTS AND DISCUSSION}

Simulations are done using Simulink, MATLAB software for a period of 100 seconds. The multi-source single-area power system is subjected to a $1 \%(0.01 \mathrm{pu})$ load disturbance using each classically and meta-heuristically tuned controllers. First, for an uncontrolled power system, the frequency dropped and eventually settled at $49.37 \mathrm{~Hz}$ for a load disturbance of 0.01pu, as shown in Fig. 8(a). This deviation in frequency of the power system after the governors took action doesn't mean there is a lack of generation power but it is due to the characteristics of the governor, especially when the frequency deviation is small (Dinakin and Oluseyi, 2018). As seen in Fig. 8(b), the total power generation for a load disturbance of $0.01 \mathrm{pu}$ is $0.0072 \mathrm{pu}$ and this is inadequate.

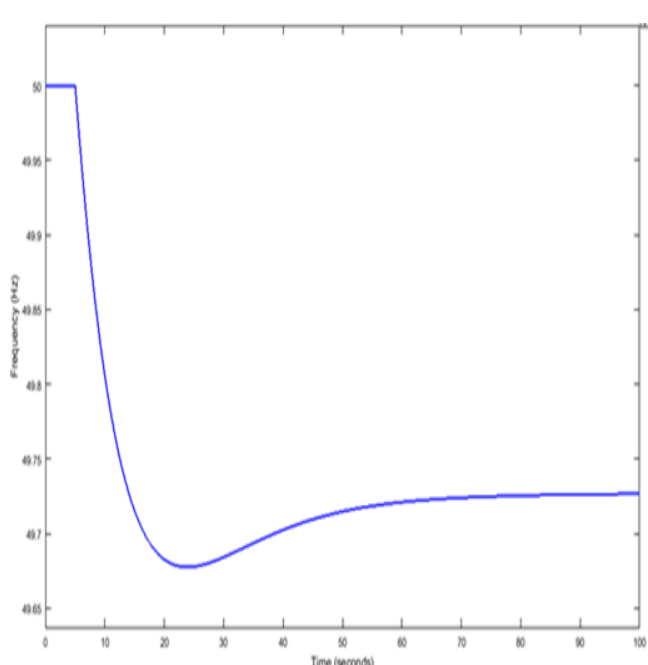

(a) frequency

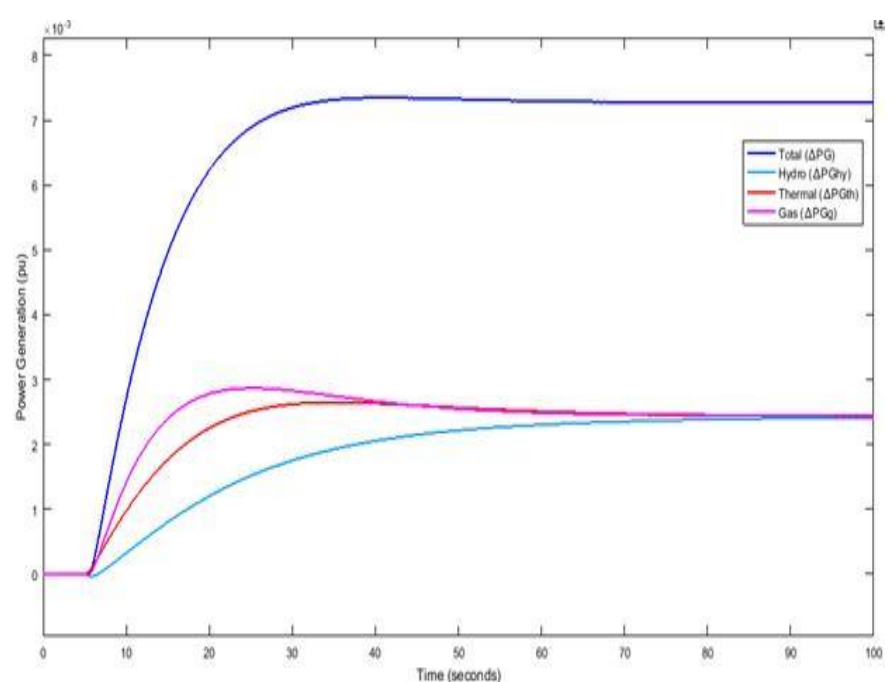

(b) power generation

Fig. 8. Output for an uncontrolled system.

The power generation outputs for a $1 \%$ load disturbance, as a result of each controller action, for an equal participation factor for each source of 0.3333, are shown in Fig. 9 (a-d). 


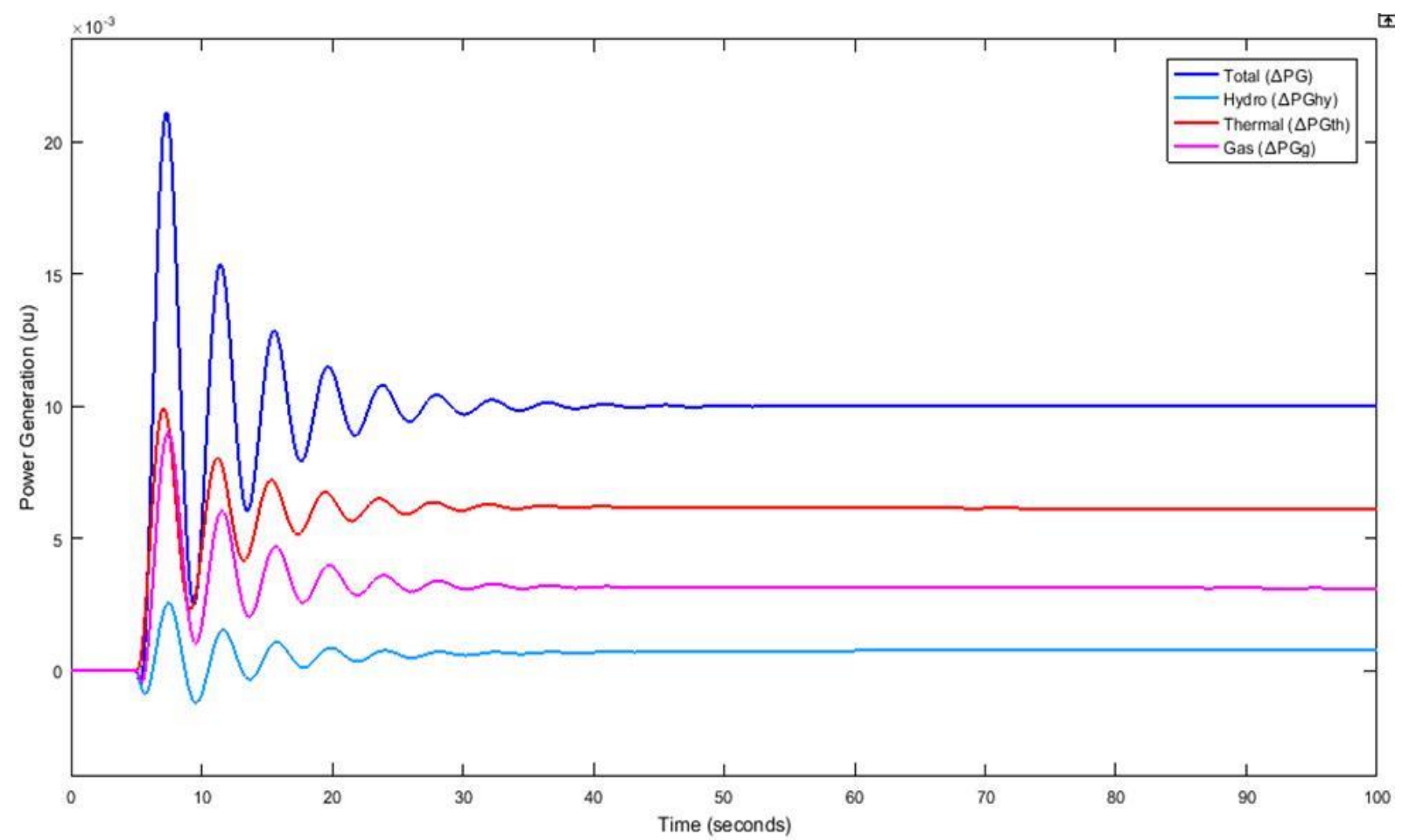

(a) Ziegler-Nichols open loop method

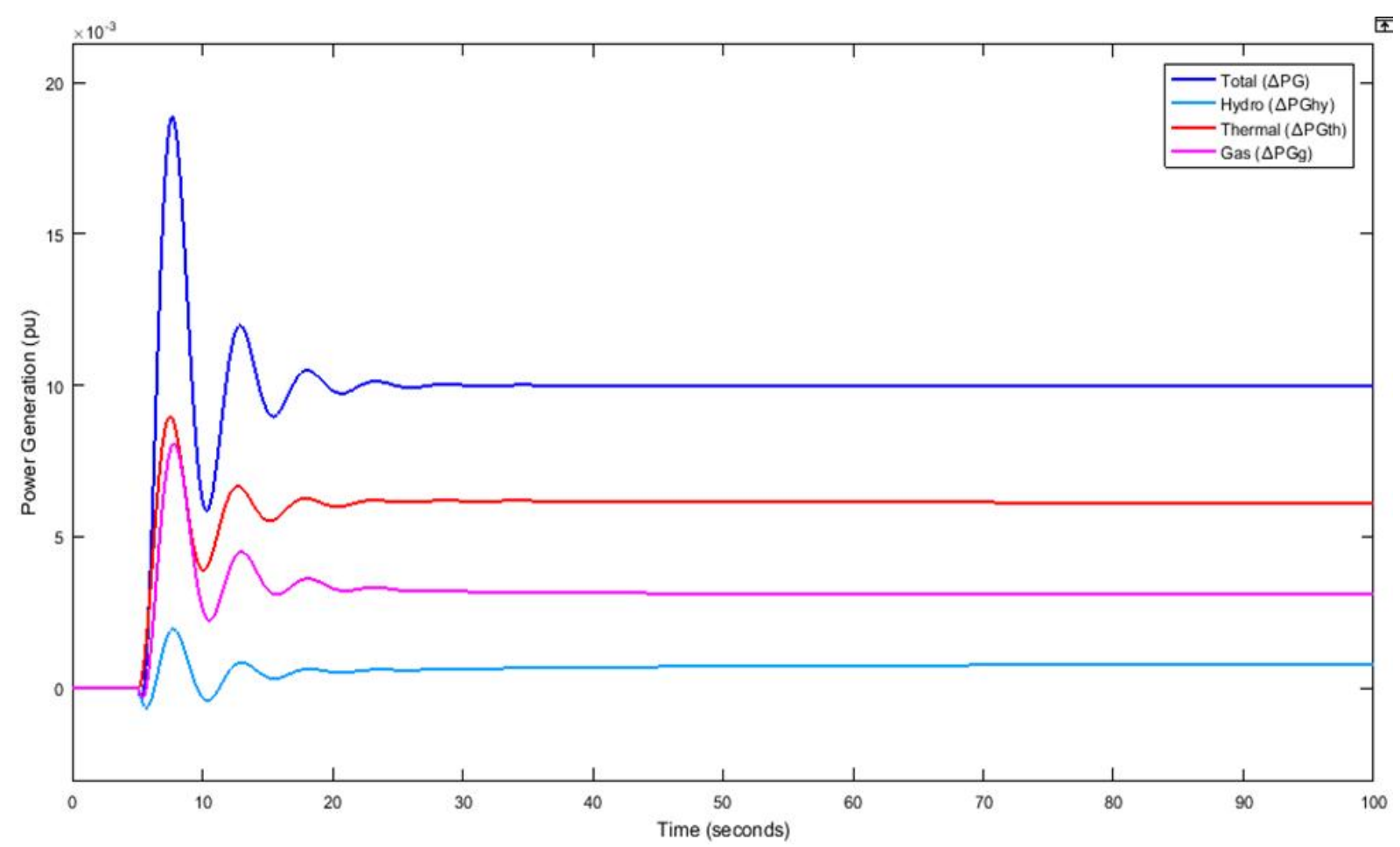

(b) Chien-Hrones-Reswick load rejection method

Fig. 9. Power generation outputs for a $1 \%$ load disturbance. 


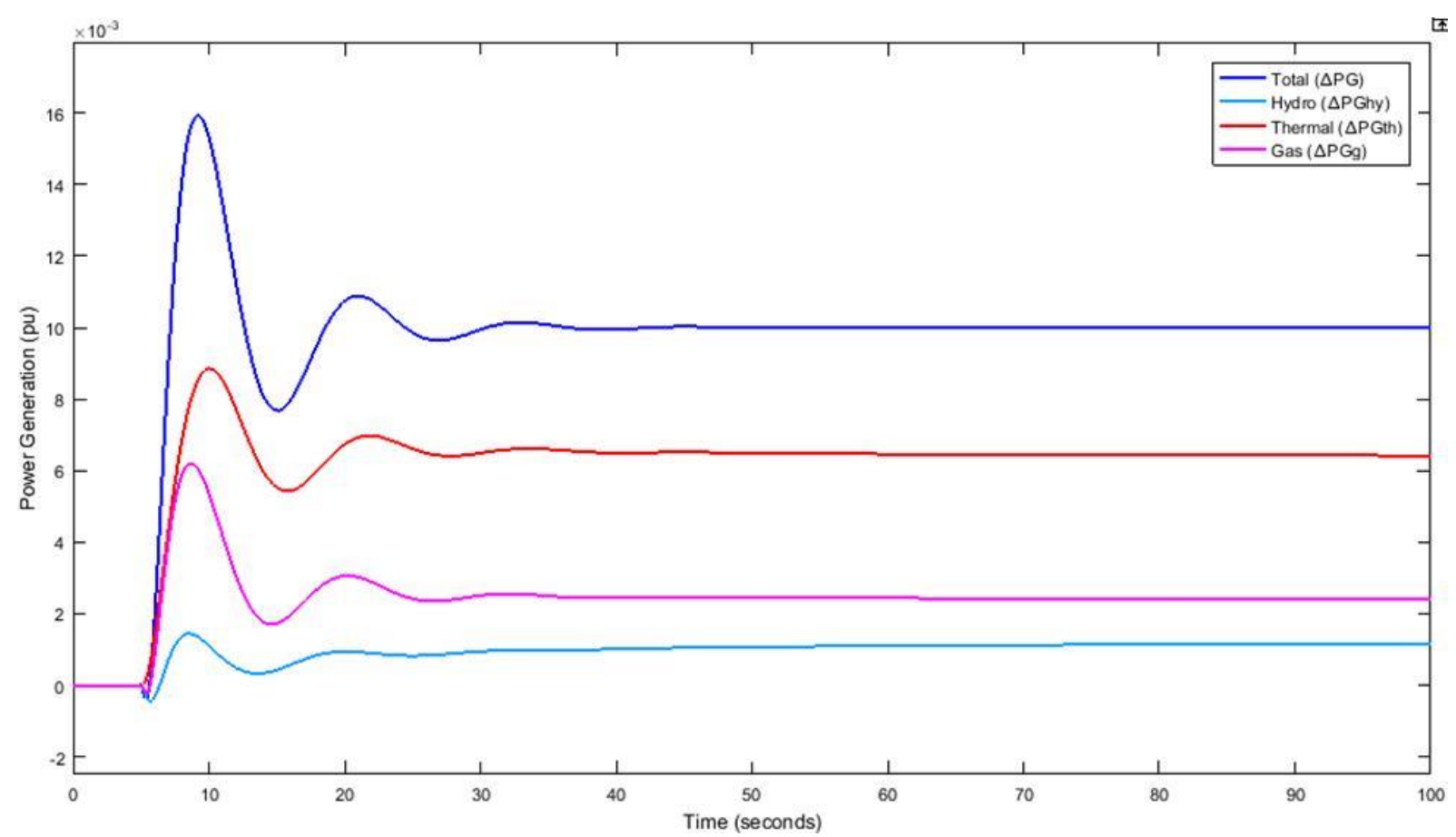

(c) Ziegler-Nichols closed loop method

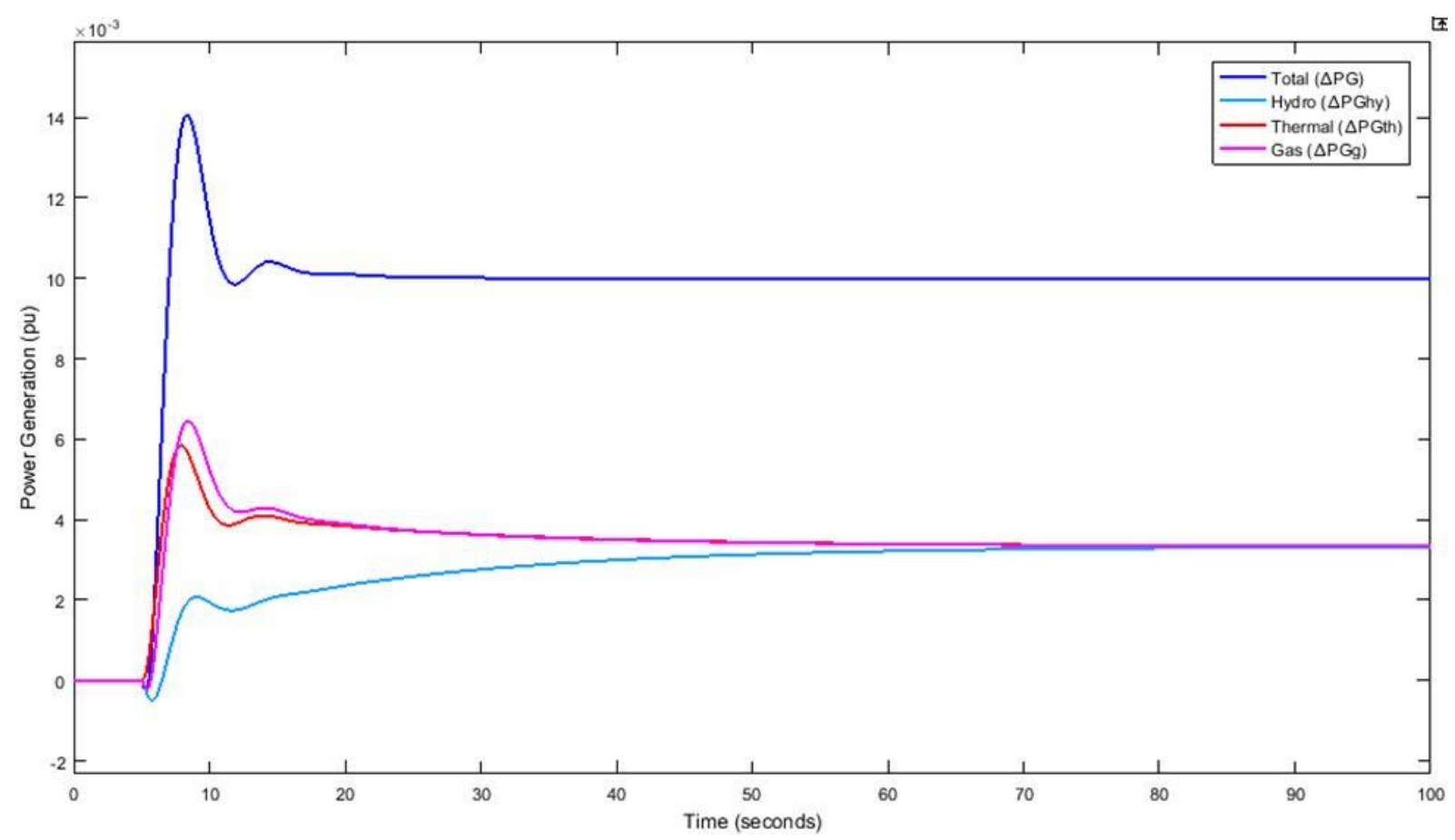

(d) Fuzzy-PID

Fig. 9. Continued...

From the power generation plots, it is noticed that there is an uneven balance in generation from both $\mathrm{ZN}$ tuning methods and $\mathrm{C}-\mathrm{H}-\mathrm{R}$ method despite the participation factors being equal. The thermal source results in the highest generation output for all three methods with a generation output of $0.0061 \mathrm{pu}$ for the $\mathrm{ZN}$ open loop method, $0.0061 \mathrm{pu}$ for the C-H-R method and $0.0064 \mathrm{pu}$ for the $\mathrm{ZN}$ closed loop method. The generation from the gas source is next to the thermal source 
with $0.0031 \mathrm{pu}, 0.0031 \mathrm{pu}, 0.0024 \mathrm{pu}$ for the $\mathrm{ZN}$ open loop, C-H-R and ZN closed loop methods respectively. While the hydro source produces the least power with $0.0008 \mathrm{pu}$ for the $\mathrm{ZN}$ open loop method, 0.0008pu for the C-H-R method and 0.0011pu for the $\mathrm{ZN}$ closed loop method. On the contrary, the Fuzzy-PID controller achieves a balanced generation from each source with an output of 0.0033 pu after approximately 60 seconds from the time the system was subjected to the load disturbance. The participation factors of the sources are then varied systematically. The subsequent power generation outputs of each source and the RMSE values are shown in Table 8.

Table 8. Power generation outputs and RMSE values for different participation factors and $1 \%$ load disturbance.

\begin{tabular}{|c|c|c|c|c|c|c|c|c|c|c|c|c|c|c|c|c|c|c|}
\hline \multicolumn{3}{|c|}{$\begin{array}{c}\text { Participation } \\
\text { Factors }\end{array}$} & \multicolumn{3}{|c|}{$\begin{array}{c}\text { ZN Open Loop } \\
\times 10^{-3}(\mathbf{p u}) \\
\end{array}$} & \multicolumn{3}{|c|}{$\begin{array}{c}\text { C-H-R } \\
\times 10^{-3}(\mathbf{p u}) \\
\end{array}$} & \multicolumn{3}{|c|}{$\begin{array}{c}\text { ZN Closed Loop } \\
\times 10^{-3}(\mathbf{p u}) \\
\end{array}$} & \multicolumn{3}{|c|}{$\begin{array}{l}\text { Fuzzy-PID } \\
\times 10^{-3}(\mathbf{p u}) \\
\end{array}$} & \multicolumn{4}{|c|}{ RMSE (pu) } \\
\hline $\mathbf{P F}_{\mathrm{hy}}$ & $\mathbf{P F}_{\text {th }}$ & $\mathbf{P F}_{\mathrm{g}}$ & $\mathbf{P}_{\mathrm{G}_{\mathrm{hy}}}$ & $\mathbf{P}_{\mathrm{G}_{\mathrm{th}}}$ & $\mathbf{P}_{\mathrm{G}_{\mathrm{g}}}$ & $\mathbf{P}_{\mathrm{G}_{\mathrm{hy}}}$ & $\mathbf{P}_{\mathbf{G}_{\mathrm{th}}}$ & $\mathbf{P}_{\mathrm{G}_{\mathrm{g}}}$ & $\mathbf{P}_{\mathrm{G}_{\mathrm{hy}}}$ & $\mathbf{P}_{\mathrm{G}_{\mathrm{th}}}$ & $\mathbf{P}_{\mathbf{G}_{\mathrm{g}}}$ & $\mathbf{P}_{\mathrm{G}_{\mathrm{hy}}}$ & $\mathbf{P}_{\mathrm{G}_{\text {th }}}$ & $\mathbf{P}_{\mathbf{G}_{\mathrm{g}}}$ & ZN OL & C-H-R & ZN CL & $\begin{array}{c}\text { Fuzzy- } \\
\text { PID }\end{array}$ \\
\hline 0.1 & 0.1 & 0.8 & \multicolumn{3}{|c|}{ Unstable } & 0.2 & 1.9 & 7.8 & 0.4 & 2.4 & 7.2 & 1.0 & 1.0 & 8.0 & - & 0.00070 & 0.00098 & $1 \mathrm{e}-05$ \\
\hline 0.1 & 0.2 & 0.7 & \multicolumn{3}{|c|}{ Unstable } & 0.2 & 3.5 & 6.3 & 0.4 & 4.1 & 5.5 & 1.0 & 2.0 & 7.0 & - & 0.00107 & 0.00156 & $1 \mathrm{e}-05$ \\
\hline 0.1 & 0.3 & 0.6 & 0.2 & 4.9 & 4.9 & 0.2 & 4.9 & 4.9 & 0.3 & 5.5 & 4.2 & 1.0 & 3.0 & 6.0 & 0.00132 & 0.00132 & 0.00184 & $1 \mathrm{e}-05$ \\
\hline 0.1 & 0.4 & 0.5 & 0.2 & 6.0 & 3.8 & 0.2 & 6.0 & 3.8 & 0.3 & 6.6 & 3.1 & 1.0 & 4.0 & 5.0 & 0.00142 & 0.00142 & 0.00190 & $1 \mathrm{e}-05$ \\
\hline 0.1 & 0.5 & 0.4 & 0.2 & 7.0 & 2.8 & 0.2 & 7.0 & 2.8 & 0.3 & 7.5 & 2.3 & 1.0 & 5.0 & 4.0 & 0.00141 & 0.00141 & 0.00180 & $1 \mathrm{e}-05$ \\
\hline 0.1 & 0.6 & 0.3 & 0.2 & 7.8 & 2.0 & 0.2 & 7.8 & 2.0 & 0.2 & 8.2 & 1.5 & 1.0 & 6.0 & 3.0 & 0.00130 & 0.00130 & 0.00158 & $1 \mathrm{e}-05$ \\
\hline 0.1 & 0.7 & 0.2 & 0.2 & 8.6 & 1.2 & 0.2 & 8.6 & 1.2 & 0.2 & 8.8 & 1.0 & 1.0 & 7.0 & 2.0 & 0.00113 & 0.00113 & 0.00129 & $1 \mathrm{e}-05$ \\
\hline 0.1 & 0.8 & 0.1 & 0.1 & 9.3 & 0.6 & 0.1 & 9.3 & 0.6 & 0.2 & 9.3 & 0.4 & 1.0 & 8.0 & 1.0 & 0.00091 & 0.00091 & 0.00096 & $1 \mathrm{e}-05$ \\
\hline 0.2 & 0.1 & 0.7 & \multicolumn{3}{|c|}{ Unstable } & 0.5 & 2.1 & 7.4 & 0.9 & 2.5 & 6.6 & 2.0 & 1.0 & 7.0 & - & 0.00108 & 0.00109 & $1 \mathrm{e}-05$ \\
\hline 0.2 & 0.2 & 0.6 & 0.5 & 3.8 & 5.8 & 0.5 & 3.8 & 5.7 & 0.8 & 4.3 & 4.9 & 2.0 & 2.0 & 6.0 & 0.00135 & 0.00135 & 0.00164 & $1 \mathrm{e}-05$ \\
\hline 0.2 & 0.3 & 0.5 & 0.4 & 5.2 & 4.4 & 0.4 & 5.2 & 4.4. & 0.7 & 5.7 & 3.6 & 2.0 & 3.0 & 5.0 & 0.00158 & 0.00159 & 0.00192 & $1 \mathrm{e}-05$ \\
\hline 0.2 & 0.4 & 0.4 & 0.4 & 6.4 & 3.2 & 0.4 & 6.4 & 3.2 & 0.6 & 6.8 & 2.6 & 2.0 & 4.0 & 4.0 & 0.00170 & 0.00170 & 0.00199 & $1 \mathrm{e}-05$ \\
\hline 0.2 & 0.5 & 0.3 & 0.4 & 7.4 & 2.2 & 0.4 & 7.4 & 2.2 & 0.6 & 7.7 & 1.7 & 2.0 & 5.0 & 3.0 & 0.00172 & 0.00172 & 0.00191 & $1 \mathrm{e}-05$ \\
\hline 0.2 & 0.6 & 0.2 & 0.4 & 8.3 & 1.4 & 0.3 & 8.3 & 1.4 & 0.5 & 8.4 & 1.1 & 2.0 & 6.0 & 2.0 & 0.00165 & 0.00165 & 0.00173 & $1 \mathrm{e}-05$ \\
\hline 0.2 & 0.7 & 0.1 & 0.3 & 9.0 & 0.7 & 0.3 & 9.0 & 0.7 & 0.5 & 9.0 & 0.5 & 2.0 & 7.0 & 1.0 & 0.00152 & 0.00152 & 0.00150 & $1 \mathrm{e}-05$ \\
\hline 0.3 & 0.1 & 0.6 & \multicolumn{3}{|c|}{ Unstable } & 0.9 & 2.3 & 6.9 & 1.4 & 2.6 & 5.9 & 3.0 & 1.0 & 6.0 & - & 0.00152 & 0.00130 & $1 \mathrm{e}-05$ \\
\hline 0.3 & 0.2 & 0.5 & 0.8 & 4.1 & 5.2 & 0.8 & 4.1 & 5.2 & 1.2 & 4.5 & 4.3 & 3.0 & 2.0 & 5.0 & 0.00175 & 0.00175 & 0.00182 & $1 \mathrm{e}-05$ \\
\hline 0.3 & 0.3 & 0.4 & 0.7 & 5.5 & 3.8 & 0.7 & 5.5 & 3.8 & 1.1 & 5.9 & 3.0 & 3.0 & 3.0 & 4.0 & 0.00198 & 0.00198 & 0.00210 & $1 \mathrm{e}-05$ \\
\hline 0.3 & 0.4 & 0.3 & 0.7 & 6.8 & 2.6 & 0.7 & 6.8 & 2.6 & 1.0 & 7.0 & 2.0 & 3.0 & 4.0 & 3.0 & 0.00211 & 0.00211 & 0.00219 & $1 \mathrm{e}-05$ \\
\hline 0.3 & 0.5 & 0.2 & 0.6 & 7.8 & 1.6 & 0.6 & 7.8 & 1.6 & 0.9 & 7.9 & 1.2 & 3.0 & 5.0 & 2.0 & 0.00215 & 0.00215 & 0.00215 & $1 \mathrm{e}-05$ \\
\hline 0.3 & 0.6 & 0.1 & 0.6 & 8.7 & 0.7 & 0.6 & 8.7 & 0.7 & 0.8 & 8.7 & 0.5 & 3.0 & 6.0 & 1.0 & 0.00211 & 0.00211 & 0.00202 & $1 \mathrm{e}-05$ \\
\hline 0.4 & 0.1 & 0.5 & 1.3 & 2.5 & 6.3 & 1.3 & 2.5 & 6.3 & 2.0 & 2.8 & 5.2 & 4.0 & 1.0 & 5.0 & 0.00194 & 0.00194 & 0.00154 & $1 \mathrm{e}-05$ \\
\hline 0.4 & 0.2 & 0.4 & 1.1 & 4.4 & 4.5 & 1.1 & 4.4 & 4.5 & 1.7 & 4.7 & 3.6 & 4.0 & 2.0 & 4.0 & 0.00218 & 0.00218 & 0.00206 & $1 \mathrm{e}-05$ \\
\hline 0.4 & 0.3 & 0.3 & 1.0 & 6.0 & 3.0 & 1.0 & 6.0 & 3.0 & 1.5 & 6.2 & 2.3 & 4.0 & 3.0 & 3.0 & 0.00242 & 0.00242 & 0.00236 & $1 \mathrm{e}-05$ \\
\hline 0.4 & 0.4 & 0.2 & 0.9 & 7.2 & 1.8 & 0.9 & 7.2 & 1.8 & 1.3 & 7.3 & 1.4 & 4.0 & 4.0 & 2.0 & 0.00258 & 0.00258 & 0.00248 & $1 \mathrm{e}-05$ \\
\hline 0.4 & 0.5 & 0.1 & 0.9 & 8.3 & 0.8 & 0.9 & 8.3 & 0.8 & 1.2 & 8.2 & 0.6 & 4.0 & 5.0 & 1.0 & 0.00264 & 0.00264 & 0.00246 & $1 \mathrm{e}-05$ \\
\hline 0.5 & 0.1 & 0.4 & 1.7 & 2.7 & 5.5 & 1.7 & 2.7 & 5.5 & 2.7 & 2.9 & 4.4 & 5.0 & 1.0 & 4.0 & 0.00230 & 0.00230 & 0.00176 & $1 \mathrm{e}-05$ \\
\hline 0.5 & 0.2 & 0.3 & 1.5 & 4.8 & 3.7 & 1.5 & 4.8 & 3.7 & 2.3 & 4.9 & 2.8 & 5.0 & 2.0 & 3.0 & 0.00260 & 0.00260 & 0.00233 & $1 \mathrm{e}-05$ \\
\hline 0.5 & 0.3 & 0.2 & 1.4 & 6.4 & 2.2 & 1.4 & 6.4 & 2.2 & 2.0 & 6.4 & 1.6 & 5.0 & 3.0 & 2.0 & 0.00289 & 0.00289 & 0.00266 & $1 \mathrm{e}-05$ \\
\hline 0.5 & 0.4 & 0.1 & 1.2 & 7.8 & 1.0 & 1.2 & 7.8 & 1.0 & 1.7 & 7.6 & 0.7 & 5.0 & 4.0 & 1.0 & 0.00307 & 0.00307 & 0.00280 & $1 \mathrm{e}-05$ \\
\hline 0.6 & 0.1 & 0.3 & 2.3 & 3.0 & 4.6 & 2.3 & 3.0 & 4.6 & 3.4 & 3.1 & 3.5 & 6.0 & 1.0 & 3.0 & 0.00260 & 0.00260 & 0.00196 & $1 \mathrm{e}-05$ \\
\hline 0.6 & 0.2 & 0.2 & 2.0 & 5.3 & 2.7 & 2.0 & 5.3 & 2.7 & 2.8 & 5.2 & 2.0 & 6.0 & 2.0 & 2.0 & 0.00300 & 0.00300 & 0.00260 & $1 \mathrm{e}-05$ \\
\hline 0.6 & 0.3 & 0.1 & 1.8 & 7.0 & 1.2 & 1.8 & 7.0 & 1.2 & 2.4 & 6.7 & 0.8 & 6.0 & 3.0 & 1.0 & 0.00336 & 0.00336 & 0.00297 & $1 \mathrm{e}-05$ \\
\hline 0.7 & 0.1 & 0.2 & 3.1 & 3.4 & 3.5 & 3.1 & 3.4 & 3.5 & 4.2 & 3.3 & 2.5 & 7.0 & 1.0 & 2.0 & 0.00280 & 0.00280 & 0.00211 & $1 \mathrm{e}-05$ \\
\hline 0.7 & 0.2 & 0.1 & 2.6 & 5.9 & 1.5 & 2.6 & 5.9 & 1.5 & 3.5 & 5.5 & 1.0 & 7.0 & 2.0 & 1.0 & 0.00338 & 0.00338 & 0.00285 & $1 \mathrm{e}-05$ \\
\hline 0.8 & 0.1 & 0.1 & 4.0 & 3.9 & 2.0 & 4.1 & 3.9 & 2.0 & 5.1 & 3.5 & 1.3 & 8.0 & 1.0 & 1.0 & 0.00290 & 0.00290 & 0.00220 & $1 \mathrm{e}-05$ \\
\hline
\end{tabular}

Again, it is seen from Table 8 that the PID controller tuned by the ZN methods and the C-H-R methods result in uneven balance with the participation factors. It is also seen that the $\mathrm{ZN}$ open loop method exhibited some unstable system states for four different participation factor combinations. The fuzzy logic tuned PID controller, on the other hand, achieved approximately exact balance of power generation from each source in proportion to its participation factor. 
The average generation outputs of each source from Table 8 are represented by the bar chart in Fig 10(a) while the average RMSE is shown in Fig. 10(b).

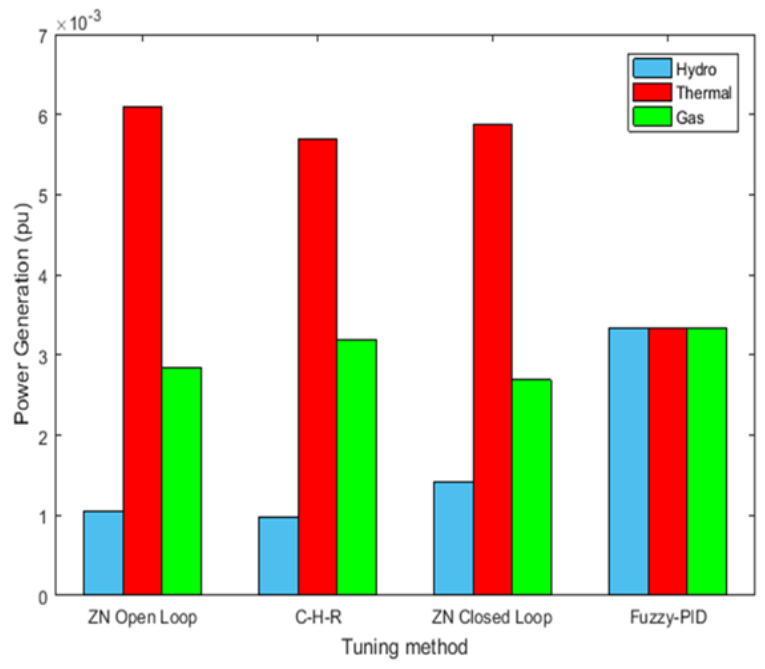

(a) generation outputs

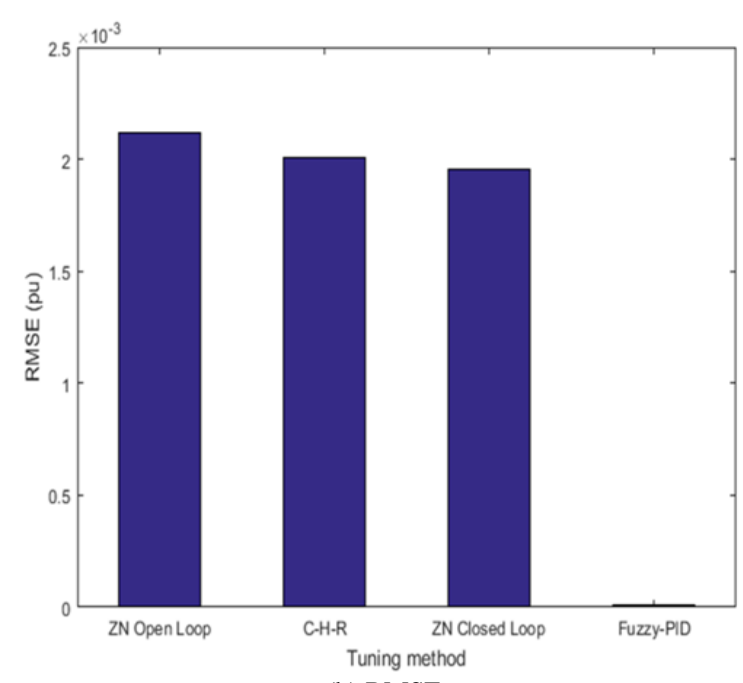

(b) RMSE

Fig. 10. Bar chart representation of average generation and average RMSE.

In order to achieve a balance between generation and load demand, the ACE must be equal to zero. For a load disturbance of $1 \%$, the ACE based on the action of each controller is shown in Fig. 11(a). It is observed that each controller successfully achieved a zero ACE, thus indicating that total power generation equals load demand. The resulting frequency deviations $(\triangle \mathrm{f})$, in Hertz (Hz), are shown in Fig. 11(b).

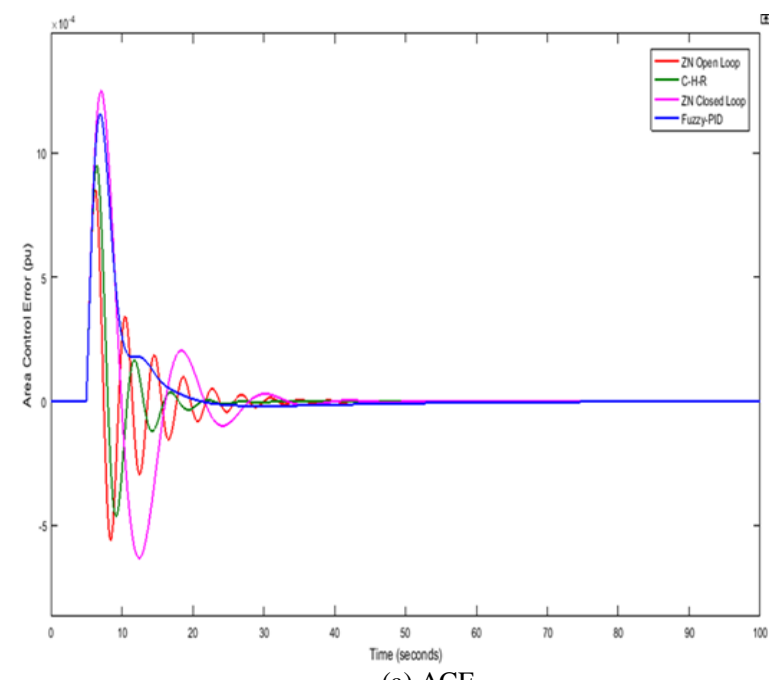

(a) ACE

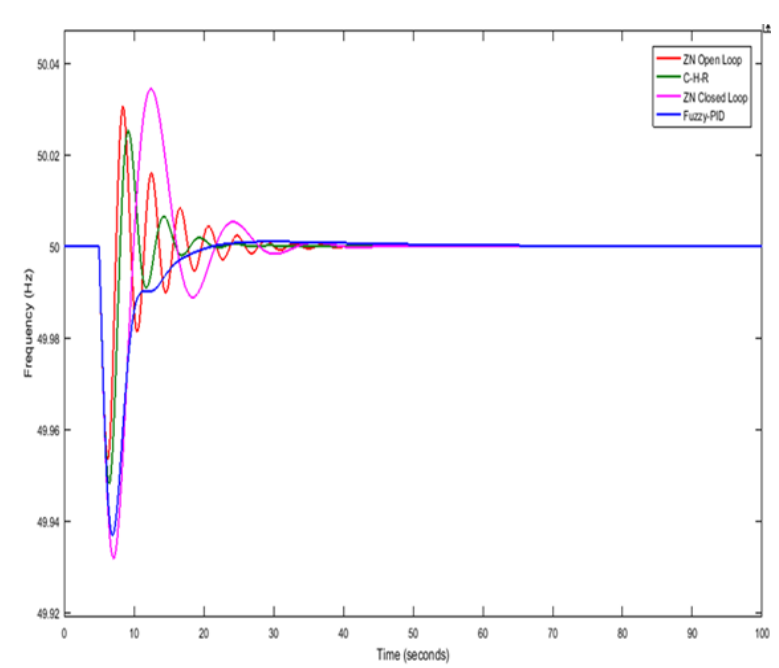

(b) frequency deviation plot

Fig. 11. Controller responses to $1 \%$ load disturbance.

All simulations above were done for a load disturbance of $+1 \%$. It is also necessary to ascertain that the controllers can adequately deal with negative load disturbances. Therefore, Fig. 12 shows the frequency deviation for a load disturbance of $1 \%$ applied after 5 seconds and a load disturbance of $-1 \%$ applied after 50 seconds. 


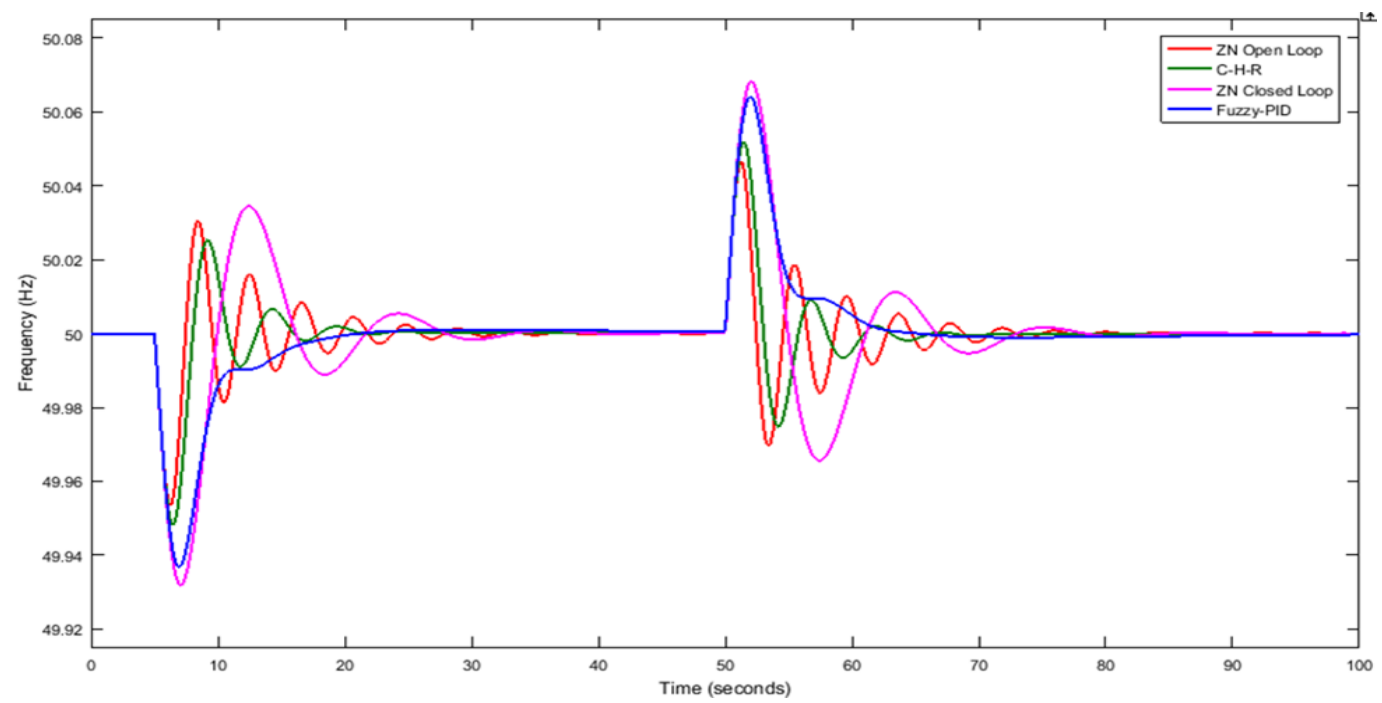

Fig. 12. Frequency response for $+1 \%$ load disturbance and $-1 \%$ load disturbance for each tuned controller.

It is observed that for negative load disturbances, a mirror image of the frequency deviation of the corresponding positive load disturbance is achieved. The dynamic performance of the controllers is determined using the performance indices: ISE, IAE, ITAE and ITSE, with the frequency deviation, in $\mathrm{Hz}$, taken as the error function, $\mathrm{e}(\mathrm{t})$. The values obtained are shown in Table 9.

Table 9. Performance comparison of the tuned controllers.

\begin{tabular}{cccccc}
\hline Tuning method & ISE & IAE & ITAE & ITSE & Settling time \\
\hline ZN open loop & 0.0044 & 0.2072 & 1.2980 & 0.0134 & 24.63 \\
C-H-R & 0.0049 & 0.1741 & 0.7084 & 0.0107 & 15.44 \\
ZN closed loop & 0.0148 & 0.4077 & 2.7730 & 0.0575 & 26.28 \\
Fuzzy-PID & 0.0099 & 0.2862 & 2.0900 & 0.0251 & 13.67 \\
\hline
\end{tabular}

From Table 9, it is seen that the ZN open loop tuned PID controller achieved the best ISE value while the controller tuned using the $\mathrm{C}-\mathrm{H}-\mathrm{R}$ load rejection method achieved the best IAE, ITAE and ITSE values. The Fuzzy-PID controller had the fastest frequency settling time.

\section{CONCLUSION}

A performance comparison of classical techniques and meta-heuristic technique for PID tuning has been presented. The comparison was done for automatic generation control (AGC) of a multi-source single area power system. Each source contributed to total power generation based on its participation factor. The RMSE error was used to estimate generation proportionality with participation factor. With a RMSE value of approximately 1e-05, the Fuzzy Logic tuned PID controller achieved the most proportional generation balance. This was followed by the 
ZN closed loop method with a RMSE of 1.96e-03 then the C-H-R load rejection method with a RMSE of 2.0e-03 and lastly, the ZN open loop method with a RMSE 2.12e-03. For the performance dynamics of the controllers, the C-H-R load rejection method achieved the least fitness function values with ISE, IAE, ITSE and ITAE values of 0.0049, 0.1741, 0.7084 and 0.0107 respectively for a $1 \%$ load deviation. From the frequency deviation plots, the FuzzyPID controller achieved the fastest settling time of 13.67 seconds. It can therefore be concluded that for AGC of multi-source single-area power systems, PID controllers tuned using the ZN open loop method and the C-H-R load rejection method, prioritizes achieving zero ACE and lower frequency deviation over a balance between generation output of each source and its participating factor. The Fuzzy-PID controller on the other hand achieves both with great results even if there was a slightly higher fitness function values when compared with the preceding methods. ISE, IAE, ITSE and ITAE values for the Fuzzy-PID controller are 0.0099, 0.2862, 2.09 and 0.0251 respectively.

\section{ACKNOWLEDGEMENTS}

The authors appreciate the National Information Technology Development Agency (NITDA) for the research grant provided to carry out this research through the National Information Technology Development Fund (NITDEF).

\section{REFERENCES}

Abdulameer A., Sulaiman M., Aras M.S.M., Saleem D., (2016) 'GUI based control system analysis using PID controller for education' Indonesian Journal of Electrical Engineering and Computer Science, 3(1), 91-101.

Al-Odienat A.I., Al-Lawama A.A., (2008) 'The advantages of PID Fuzzy controllers over the conventional types’ American Journal of Applied Sciences, 5(6), 653-658.

Astrom K.J., Hagglund T., (1995) PID Controllers: Theory, Design and Tuning, Research Triangle Park, NC: Instrument Society of America.

Barisal A.K., Mishra S., (2017) 'Improved PSO based automatic generation control of multisource nonlinear power systems interconnected by AC/DC links' Cogent Engineering, 5, 1-20. Chandrakala V., Sukumar B., Sankaranarayanan K., (2014) 'Load frequency control of multisource multi-area hydro thermal system using flexible alternating current transmission system devices’ Electric Power Components and Systems, 42(9), 927-934.

Chen G., (1996) 'Conventional and fuzzy PID controllers: an overview’ International Journal of Intelligent Control and Systems, 1, 235-246. 
Cohn N., (1957) 'Some aspects of tie-line bias control on interconnected power systems' Transactions of the American Institute of Electrical Engineers, 75, 1415-1436.

Debnath M.J., Satapathy P., Mallick R.K., (2017) '3DOF-PID controller based automatic generation control using TLBO algorithm' International Journal of Pure and Applied Mathematics, 114(9), 39-49.

Dinakin D.D., Oluseyi P.O., (2018) 'Optimal under-frequency load curtailment via continuous load control in a single area power system using Fuzzy Logic, PID-Fuzzy and Neuro-Fuzzy (ANFIS) controllers' Jordan Journal of Electrical Engineering (JJEE), 4(4), 208-223.

Dorigo M., Gambardella L.M., (1997) 'Ant colony system: a cooperative learning approach to the travelling salesman problem' IEEE Transactions on Evolutionary Computation, 1(1), 53-66. Elsisi M., Soliman M., Aboelela M.A.S., Mansour W., (2015) 'ABC based design of PID controller for two area load frequency control with non-linearities' Indonesian Journal of Electrical Engineering and Informatics, 16(1), 55-64.

Fitri I.R., Kim J., Song H., (2017) 'High-gain disturbance observer-based robust load frequency control of power systems with multiple areas' Energies, 10(595), 1-21.

Guha D., Roy P.K., Banerjee S., (2016) 'Quasi-oppositional differential search algorithm applied to load frequency control' Engineering Science and Technology, an International Journal, 19, 1635-1654.

Jadhav A.M., Vadirajacharya K., (2012) 'Performance verification of PID controller in an interconnected power system using particle swamp optimization' Energy Procedia, $2^{\text {nd }}$ Intrnational Conference on Advances in Energy Engineering, 14, 2075-2080.

Jagatheesan K., Samanta S., Choudhury A., Dey N., Anand B., Ashour A.S., (2017) 'Quantum Inspired Evolutionary Algorithm in Load Frequency Control of Multi-area Interconnected Thermal Power System with Non-linearity'. In: Hassanien A., Elhoseny M., Kacprzyk J. (eds), Quantum Computing: An Environment for Intelligent Large Scale Real Application. Studies in Big Data. Springer, Cham 33.

Jain S., Beniwal N.S., (2015) 'Hybrid PID-Fuzzy controlling approach' International Journal of Advanced Research in Electronics and Communication Engineering (IJARECE), 4(11), 26482651.

Kumar V., Patra A., (2016) 'Application of Ziegler-Nichols method for tuning of PID controller' International Journal of Electrical and Electronics Engineering, 8(2), 559-570.

Moghadam M.A., Jalilzadeh S., (2014) 'Control of AGC in interconnected power system with diverse sources of power generation' Universal Journal of Electrical and Electronics Engineering, 2(7), 259-269. 
Oonsivilai A., Marungsri B., (2007) 'Optimal PID tuning for AGC system using adaptive Tabu search' Proceedings of the $7^{\text {th }}$ WSEAS International Conference on Power Systems, 42-47.

Osman I.H., Laporte G., (1996) ‘Metaheuristics: a bibliography’ Annals Oper. Res., 63(5), 511623.

Panigrahi T.K., Behera A., Sahoo A.K., (2017) 'Novel approach to automatic generation control with various non-linearities using 2-degree-of-freedom PID controller' Energy Procedia, 2017 International Conference on Alternative Energy in Developing Countries and Emerging Economies AEDCEE, Bangkok, Thailand, 138, 464-469.

Panwar A., Chahar S., (2016) 'Automatic load frequency control of three area power system using artificial intelligence' 2016 International Conference on Micro-Electronics and Telecommunication Engineering (ICMETE), 320-324.

Pradhan P.C., Satapathy N., Pany P.K., Moharana J., (2017) 'Automatic generation control with Z-N tuned PID controller in the two area power system with energy storage unit' International Journal of Advanced Research in Electrical, Electronics and Instrumentation Engineering, 6(5), 3640-3647.

Rahman M.M., Chowdhury A.H., Hossain M.A., (2017) 'Improved load frequency control using a fast acting active disturbance rejection controller' Energies, 10(1718), 1-18.

Rajesh K.S., Rajagopal R., (2017) 'Hybrid improved firefly-pattern search optimized fuzzy aided PID controller for automatic generation control of power systems with multi-type generations' Swarm and Evolutionary Computation, 1-12.

Reusch B., (2006) Computational Intelligence: Theory and Applications, Int. Conf., $5^{\text {th }}$ Fuzzy Days (Advances in Intelligent and Soft Computing) Springer.

Sahu R.K., Gorripotu T.S., Panda S., (2016) 'AGC of multi-area power systems with diverse energy sources using Teaching Learning Based Optimization algorithm' Engineering, Science and Technology, an International Journal, 19, 113-134.

Sarumathi S., Iqbal M.M, Venkatesan V., (2016) 'Linearized transfer function model of industrial heavy duty gas turbine plants' IEEE Digital Explorer. 7, 542-547.

Shakrokhi M., Zomorrodi A., (2012) 'Comparison of PID controller tuning methods'.

Singh A., Singh R., (2014) 'Load frequency controller of electrical power plant using ZieglerNichols $(\mathrm{ZN})$ tuning controller' International Journal of Innovative Science, Engineering and Technolology (IJISET), 1(6), 71-75.

Thapar R., (2015) 'Hydro-Turbine Governing System'. In: O.D. Thapar, Modern Hydroelectric Engineering Practice in India: Electro-mechanical Works, 1, 147-173, available: 
https://www.iitr.ac.in/departments/AH/pages/Publications_Downloads+Modern_Hydroelectric _Engg_Practice_by_Prof_OD_Thapar.html

Ziegler J.G., Nichols N.B., (1942) 'Optimum settings for automatic controllers' Transactions of the American Society of Mechanical Engineers ASME, 64, 759-768. 